\title{
Kinetics of Dynamic Recrystallization in AA2024 Aluminum Alloy
}

\author{
Xiaoxun Zhang ${ }^{1}$, Fang $\mathrm{Ma}^{2}$, Wenfeng Zhang ${ }^{1} \& \mathrm{Xia} \mathrm{Li}^{1}$ \\ ${ }^{1}$ School of Materials Engineering, Shanghai University of Engineering Science, Shanghai, China \\ ${ }^{2}$ College of Automotive Engineering, Shanghai University of Engineering Science, Shanghai, China \\ Correspondence: Xiaoxun Zhang, School of Materials Engineering, Shanghai University of Engineering Science, \\ 333 Longteng Road, Songjiang District, Shanghai 201620, China. Tel: 86-21-6779-1202. E-mail: \\ xx.zhang.cn@gmail.com
}

Received: August 10, 2014

Accepted: August 24, $2014 \quad$ Online Published: September 4, 2014

doi:10.5539/mas.v8n6p47

URL: http://dx.doi.org/10.5539/mas.v8n6p47

\begin{abstract}
Understanding the deformation mechanism of aluminum alloys is very important for the transportation and aerospace industries. In the present study, the flow stress-strain curves for AA2024 aluminum alloy were obtained by compressive tests performed on Gleeble- 3500 thermo-mechanical machine at temperatures from 250 to $450{ }^{\circ} \mathrm{C}$, strain rates from 0.01 to $10 \mathrm{~s}^{-1}$. The dynamic recrystallization (DRX) kinetics was analyzed and the flow stress model characterizing dynamic recrystallization for AA2024 aluminum alloy was put forward. The flow stress curve at elevated temperature was described as three stages, i.e. hardening, softening and stable stages. The characteristic parameters for dynamic recrystallization in the flow stress model were described as function of Zener-Hollomon parameter. By analyzing the dynamic recrystallization region of flow stress curve, the kinetics of dynamic recrystallization was revealed.
\end{abstract}

Keywords: Aluminum alloy, flow stress, dynamic recrystallization, activation energy, constitutive model

\section{Introduction}

AA2024 aluminum alloys have used for a wide variety of applications in the transportation and aerospace industries because of their distinguished physical and mechanical properties such as lightweight, high specific strength and specific rigidity. By the processes of annealing and subsequent heat treatment, AA2024 aluminum alloy has become one of the strongest aluminum alloys (DeGarmo, et al, 2003; Tajally \& Huda, 2011). Many aluminum alloys experience a dynamic recrystallization (DRX) process during hot deformation. A lot of efforts were made by researchers on the effect of homogenizing treatment and small additions of other elements on the recrystallization of $\mathrm{Al}-\mathrm{Zn}-\mathrm{Mg}$ aluminum alloys, and the influence of heating rate on the recrystallized grain size in two $\mathrm{Al}-\mathrm{Zn}-\mathrm{Mg}-\mathrm{Cu}$ aluminum alloys. However, very few efforts were made on the kinetics of dynamic recrystallization for the dispersion-hardening aluminum alloys of the $\mathrm{Al}-\mathrm{Cu}-\mathrm{Mg}$ aluminum alloys of the $2 \mathrm{XXX}$ system. These aluminum alloys have been applied extensively in the structures of aircrafts or for the manufacture of transportation vehicle parts.

A flow stress model is a substantial condition for a precise and efficient simulation of deformation behavior, such as forging, extrusion and stamping. The basis for most analytical models to describe the kinetics of recrystallization is the JMAK expression. In JMAK theory it is assumed that the recrystallized nuclei generate randomly in the matrix, and these nuclei have a constant and isotropic rate of growth. A development in theoretical study of recrystallization is on the basis of an improved understanding of the nucleation mechanism and how it is affected by microstructural heterogeneities resulting from deformation (Nes and Hutchinson, 1989; Humphreys, 1990). In a model developed by Vatne, et al (1996) and a model by Sellars (1996), the nucleation sites for recrystallized grains of different crystallographic orientations, particle stimulated nucleation and nucleation from grain boundary regions were incorporated. The microstructural parameters of the deformed structure, subgrain size, sub-boundary misorientation, were used as transient variables to correlate the recrystallization kinetics to the mechanical properties, such as strain, stress, and strain rate. In order to simulate the evolution of the recrystallization microstructures and to predict the recrystallization kinetics, many microstructural models have been developed, such as cellular models (Atkinson, 2001), computer Avrami models (Furu, et al, 1990) and the models based on the Monte Carlo (MC) (Rollett, 1997), and Cellular Automaton (CA) (Chen, et al., 2009) techniques. 
In the present study, the AA2024 aluminum alloy were uniaxially compressed at varies temperatures between 250 and $450{ }^{\circ} \mathrm{C}$ and strain rates between 0.01 and $10 \mathrm{~s}^{-1}$. The flow stress-strain curves under varies conditions were obtained. Based on these curves, we analyzed the influences of temperature and strain rate on flow stress and built up the mathematical models for flow stress and DRX of AA2024 aluminum alloy.

\section{Experimental}

\subsection{Materials}

The double-stream-pouring continuous casting (DSPCC) technology was used to prepare the AA2024 aluminum alloy ingot. The cylindrical samples were cut and obtained from the as-cast ingot. The diameter of cylindrical samples is $65 \mathrm{~mm}$ and the length is $50 \mathrm{~mm}$. These samples were homogenized at $460^{\circ} \mathrm{C}$ for 12 hours and then were pressed by the 315 ton hydraulic machine at $400^{\circ} \mathrm{C}$ to $12 \mathrm{~mm}$-thick slabs. After trimming, these slabs became $120 \mathrm{~mm} \times 150 \mathrm{~mm} \times 12 \mathrm{~mm}$ samples, and then they were rolled at $400^{\circ} \mathrm{C}$ into $10 \mathrm{~mm}$-thick sheets in the furnace. The final specimens were produced from the rolled sheet. The diameter of the final specimens is $8 \mathrm{~mm}$ and the length is $10 \mathrm{~mm}$. The chemical composition (mass fraction) of these specimens was shown in Table 1 .

Table 1. Chemical composition of AA2024 aluminum alloy

\begin{tabular}{ccccccccc}
\hline $\mathrm{Si}$ & $\mathrm{Fe}$ & $\mathrm{Cu}$ & $\mathrm{Mg}$ & $\mathrm{Zn}$ & $\mathrm{Cr}$ & $\mathrm{Ti}$ & $\mathrm{Mn}$ & $\mathrm{Al}$ \\
\hline $0.12 \sim 0.5$ & $0.15 \sim 0.5$ & $3.8 \sim 4.9$ & $1.2 \sim 1.8$ & 0.25 & 0.1 & 0.15 & $0.3 \sim 0.9$ & Balance \\
\hline
\end{tabular}

\subsection{Test Procedure}

The specimens were compressed isothermally on Gleeble-3500 thermal simulation machine at temperatures between 250 and $450{ }^{\circ} \mathrm{C}$ and strain rates between 0.01 and $10 \mathrm{~s}^{-1}$ with a height reduction of $50 \%$ to achieve the true strain of 0.7. As shown in Figure 1, four steps were adopted to process the hot compression deformation. Step 1, specimens were heated to the predetermined temperature with a rate of $5{ }^{\circ} \mathrm{C} / \mathrm{s}$. Step 2, specimens were held isothermally for $180 \mathrm{~s}$. Step 3, specimens were compressed at different strain rates to a true strain of 0.7. Step 4, the specimens were quenched immediately to room temperature after deformation. The graphite and oil were used as lubricant at the end of the specimen to reduce the effect of friction on the stress.

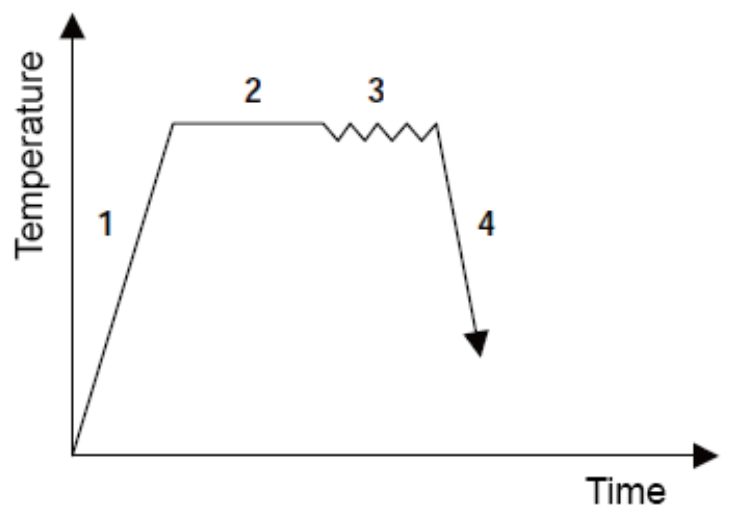

Figure 1. The processing of the hot compression deformation

\section{Results and Analyses}

\subsection{Flow Behavor}

Fig. 2 shows the flow stress-strain curves of AA2024 aluminum alloy at different temperatures and strain rates. There are three stages in the flow stress curves, namely hardening, softening and stable stages (Sheng and Shivpuri, 2006). In the first stage, the stress increases sharply with the increasement of strain, then it still goes up at a lower slop to the peak of the stress. It indicates that in the first stage of the deformation the work hardening is overwhelming. In the second stage, if the strain increases beyond a critical value, the flow stress will go down with the increasement of the strain. Then the softening stage caused by DRX will replace the hardening stage caused by work hardening until the end of the test (Liu, et al, 2008). The DRX soften the materials and the peak stess appeared in the flow stress curve indicates the initiation of DRX. In the third stage, the flow stress is stable 
which shows that the process of work hardening and softening reaches a dynamic balance. Note that although every specimen in the compressive test experience all three stages, it is not easy to tell in some cases from the flow stress curve. For example, in the case of the temperature of $450^{\circ} \mathrm{C}$ and strain rate of $10 \mathrm{~s}^{-1}$, the flow stress curve goes up sharply in the hardening stage and the reaches the stable stage, and shows that the peak stress almost equal to the correspondent flow stress. It can also be seen from Fig. 2 that the peak stress reduces with the increasement of temperature and also decrease with the decreasement of strain rate. Before reaching the peak stress, the rate of work hardening is dramatically decreased, and there will be a longer softening stage after the peak stress. The reason for this is that the increasement of temperature gives more energy to make the atomic more active, so the influence of the work hardening induced by the dislocation accumulation is remarkably reduced, and it makes the strain softening effect even stronger. The dislocation accumulation accelerates during the strain rate increasing, so a larger shear stress is required to continue the deformation of the material, therefore the flow stress will increase. Based on the above analyses, it is found that the flow stress is strain rate dependent. In addition, the deformation becomes faster when the deformation rate increases, so the softening process can not finish in a limited time period, and therefore it induces a higher flow stress.

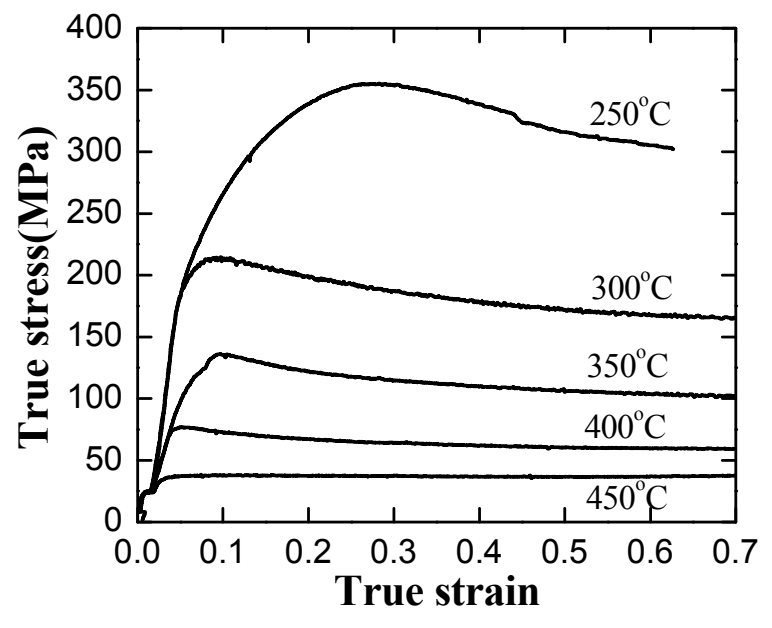

(a)

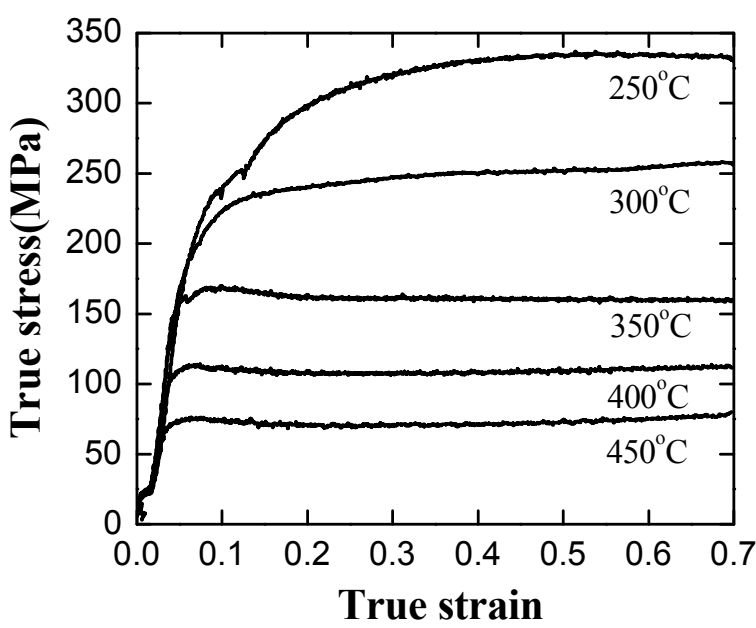

(b)

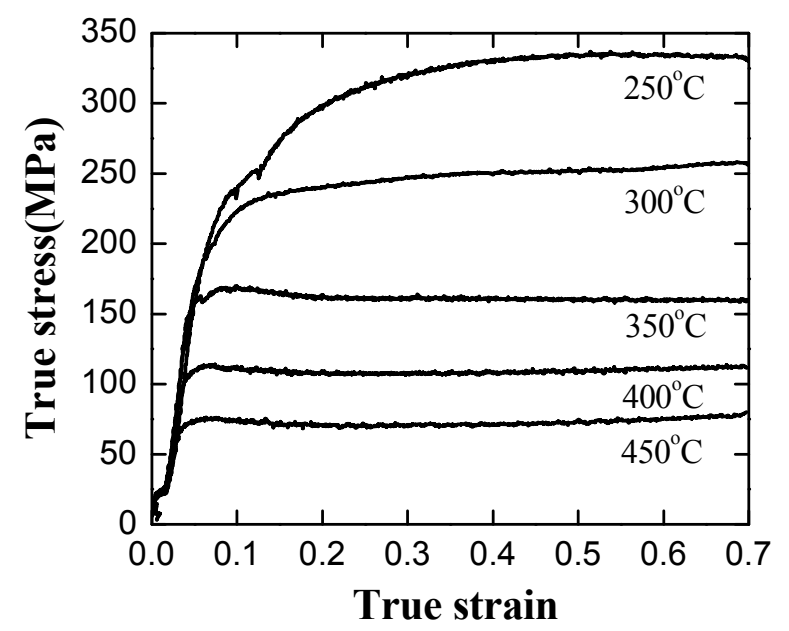

(c)

Figure 2. The true stress-true strain relationship of AA2024 under different conditions in the compressive tests: (a) $\dot{\varepsilon}=0.01 \mathrm{~s}^{-1}$, (b) $\dot{\varepsilon}=1 \mathrm{~s}^{-1}$, and (c) $\dot{\varepsilon}=10 \mathrm{~s}^{-1}$

\subsection{Kinetics Model of Dynamic Recrystallization}

In order to study the kinetics model of DRX of AA2024 aluminum alloy, the peak stresses $\sigma_{\mathrm{p}}$ and the corresponding values of $\varepsilon_{\mathrm{p}}$ at different deformation conditions were obtained from the true stress-strain curve, as show in Table 2. One of the most significant features of high-temperature plastic deformation is that the 
deformation is controlled by heat activation process. Sellars (1996) found that there is a close relationship between creeping and hot working, and the steady-state stress is a function of temperature and strain rate

$$
Z=\dot{\varepsilon} \exp \left(\frac{Q_{\text {act }}}{R T}\right)=A(\sinh (\alpha \sigma))^{n}
$$

where $Z$ is the Zener-Hollomon parameter, $Q_{\text {act }}$ is the deformation activation energy, $\dot{\varepsilon}$ is the strain rate, $R$ is the gas constant, $T$ is the temperature, $A, \alpha$ and $n$ are the material constants. The advantage of this semi-empirical model is that its parameters have obvious physical meanings, and all the parameters can be easily determined. So, this model is very popular in the hot working field and is often used as a general equation. From the plot of $\ln Z$ versus $\ln (\sinh (\alpha \sigma))$, the values of $A$ and $n$ can be determined. Before the values of $A$ and $n$ are determined, the values of $\alpha$ and $Q_{\text {act }}$ must be determined. We show the process of determining the value of $\alpha$ as follows.

The hot working obeys the power law at the high stress level and the equation is presented as follows:

$$
Z \approx A_{1} \sigma^{n^{\prime}}
$$

The favorite equation is the exponent law at the low stress level, which is given by

$$
Z \approx A_{2} \exp (\beta \sigma)
$$

Assuming $n^{\prime}=n$, the approximate value of $n$ can be obtained as the slope of the plot of $\ln \dot{\varepsilon}$ versus $\ln \sigma$ at the low stress level. It can be seen that $A=A_{2} / 2^{n}$ by comparing Eq. (1) with Eq. (3) and the value of $\alpha$ is approximately equal to $\alpha=\beta / n$. The value of $A_{2}$ and $\beta$ can be determined according to the $\ln \dot{\varepsilon}$ versus $\sigma$ plot at the high stress level. From Eq.(1), we have:

$$
\ln \dot{\varepsilon}+\frac{Q_{\text {act }}}{R T}=n \cdot \ln (\sinh (\alpha \sigma))+\ln A
$$

The above Eq.(4) can be written as

where $B$ is a constant. For a certain temperature $T$, it gives

$$
\ln \dot{\varepsilon}=n \cdot \ln (\sinh (\alpha \sigma))+B
$$

$$
n=\left[\frac{\partial \ln \dot{\varepsilon}}{\partial \ln (\sinh (\alpha \sigma))}\right]_{T}
$$

It also can be derived from Eq.(4) that

$$
\frac{Q_{\text {act }}}{R}=n \cdot\left[\frac{\partial(\ln (\sinh (\alpha \sigma)))}{\partial\left(\frac{1}{T}\right)}\right]_{\dot{\varepsilon}}
$$

Substituting Eq.(6) to Eq.(7), it derives an equation to calculate the effective activation energy for deformation:

$$
Q_{a c t}=R\left[\frac{\partial(\ln (\sinh (\alpha \sigma)))}{\partial(1 / T)}\right]_{\dot{\varepsilon}} \cdot\left[\frac{\partial \ln \dot{\varepsilon}}{\partial(\ln (\sinh (\alpha \sigma)))}\right]_{T}
$$

The first term on the right-hand side of Eq.(8) represents the slope of the $\ln (\sinh (\alpha \sigma))$ versus $1 / T$ plot and the second term represents the reciprocal value of inclination of the $\ln (\sinh (\alpha \sigma))$ versus $\ln \dot{\varepsilon}$ plot. McQueen and Ryan (2002) found that $\sigma$ can be referred to the peak stress $\sigma_{\mathrm{p}}$ or the start of steady-state stress $\sigma_{\mathrm{ss}}$ for metal with DRX. We use the peak stress $\sigma_{\mathrm{p}}$ in the present study because the peak stress $\sigma_{\mathrm{p}}$ can be easier obtained from the flow stress-strain curve than $\sigma_{\mathrm{ss}}$.

The approximate value of $n$ is 13.0652 according to the relationship $\ln \dot{\varepsilon}-\ln \sigma_{\mathrm{p}}$ as shown in Fig. 3a, and that of $\beta$ is 0.0862 according to the relationship $\ln \dot{\varepsilon}-\sigma_{\mathrm{p}}$ as shown in Fig. $3 \mathrm{~b}$. So, the value of $\alpha$ is 0.0066 . The average value of slope of the $\ln (\sinh (\alpha \sigma))-1 / T$ plot is approximately $4.8722 \times 10^{3}$ according Fig. $3 \mathrm{c}$. The reciprocal value of inclination of the $\ln (\sinh (\alpha \sigma))-\ln \dot{\varepsilon}$ plot is approximately 8.5128 according to Fig. $3 \mathrm{~d}$. So, 
the value of $Q_{\text {act }}$ equals $345 \mathrm{KJ} / \mathrm{mol}$ for AA2024 aluminum alloy.

Table 2. The peak stress and peak strain for AA2024 obtained from different process conditions

\begin{tabular}{cccc}
\hline \multirow{2}{*}{ Temperature $(\mathrm{K})$} & \multicolumn{3}{c}{$\sigma_{\mathrm{p}}(\mathrm{MPa}) / \varepsilon_{\mathrm{p}}\left(\mathrm{s}^{-1}\right)$} \\
\cline { 2 - 4 } & 0.01 & 1 & 10 \\
\hline 523 & $355.51 / 0.2825$ & - & $326.41 / 0.15547$ \\
573 & $215.03 / 0.09676$ & - & - \\
623 & $136.19 / 0.10468$ & $171.13 / 0.09706$ & $216.29 / 0.09988$ \\
673 & $76.598 / 0.05522$ & $115.09 / 0.07042$ & $155.51 / 0.03098$ \\
723 & $37.721 / 0.06976$ & $77.382 / 0.06357$ & $111.77 / 0.04007$ \\
\hline
\end{tabular}

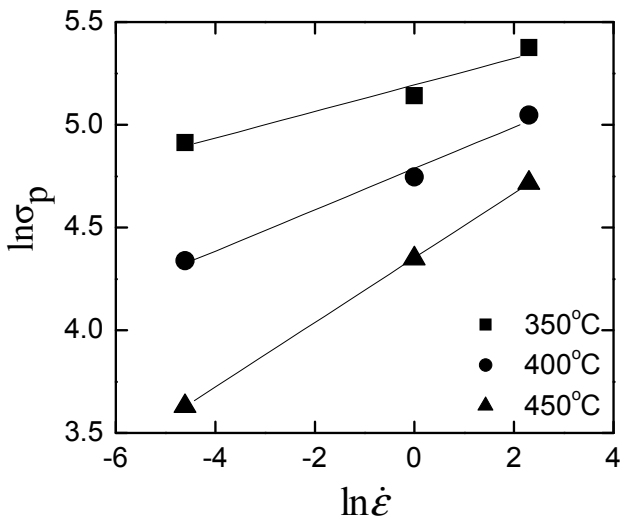

(a)

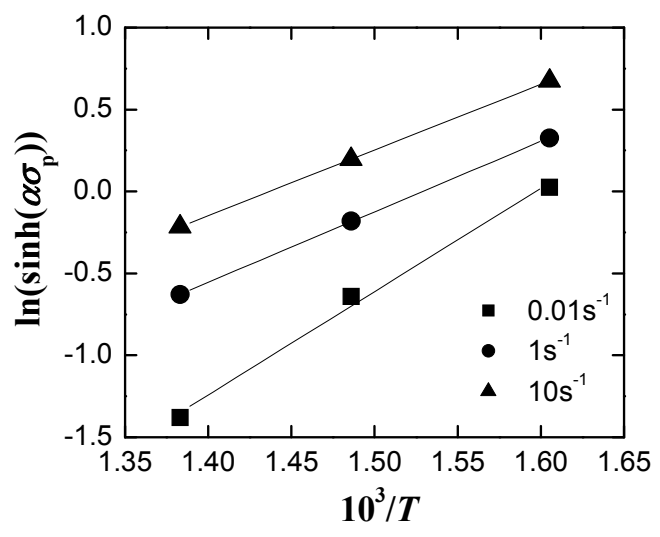

(c)

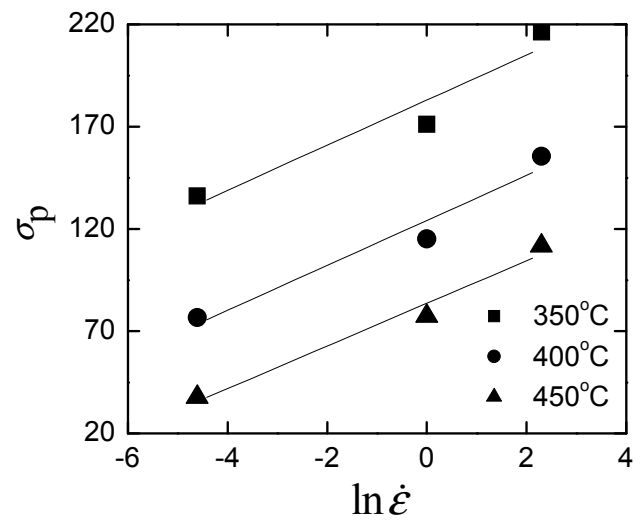

(b)

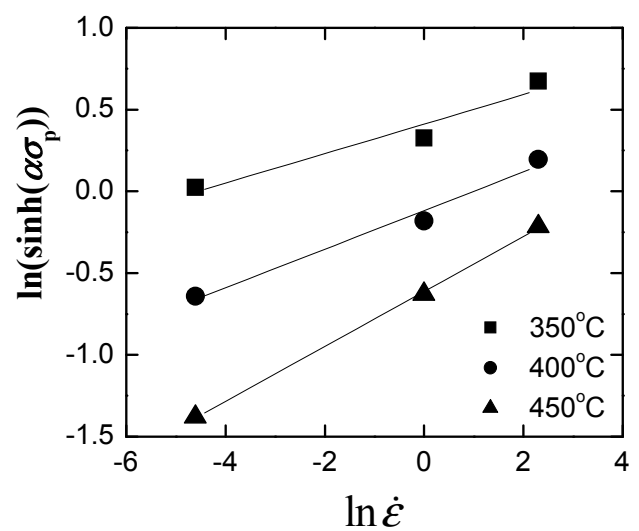

(d)

Figure 3. The relationship between flow stress, strain rate, and temperature of AA2024 aluminum alloy: (a) $\ln \sigma_{p}$ $-\ln \dot{\varepsilon},(\mathrm{b}) \sigma_{p}-\ln \dot{\varepsilon}$, (c) $\ln \left(\sinh \left(\alpha \sigma_{p}\right)\right)-1 / T,(\mathrm{~d}) \ln \left(\sinh \left(\alpha \sigma_{p}\right)\right)-\ln \dot{\varepsilon}$

\section{Discussions and Conclusions}

In this study, the true stress-true strain relationships of AA2024 aluminum alloy under different conditions from the compressive tests were obtained. The compressive tests were performed on Gleeble-3500 thermo-mechanical machine at temperatures between 250 and $450{ }^{\circ} \mathrm{C}$, strain rates between 0.01 and $10 \mathrm{~s}^{-1}$. There are three stages in the flow stress curves, namely hardening, softening and stable stages. In the first stage, the stress increases sharply with the increasement of strain, then it still goes up at a lower slop to the peak of the stress. It indicates that in the first stage of the deformation the work hardening is overwhelming. In the second stage, if the strain increases beyond a critical value, the flow stress will go down with the increasement of the strain. Then the softening stage caused by DRX will replace the hardening stage caused by work hardening until the end of the 
test. The DRX soften the materials and the peak stess appeared in the flow stress curve indicates the initiation of DRX. In the third stage, the flow stress is stable which shows that the process of work hardening and softening reaches a dynamic balance.

The peak stress reduces with the increasement of temperature and also decrease with the decreasement of strain rate, and temperature and strain rate are the two main factors influence the peak stress. The relationship between the peak stress, temperature and strain rate was established in the present study. The temperature governs the atomic diffusibility and the driving force of dislocation migration and the strain rate controls the dislocation density and the accumulation energy of the grain boundary. The relationship between peak stress, strain and flow stress was also analyzed, and the flow stress equation which can describe the dynamic recrystallization process was put forward. This flow stress equation characterized the deformation behavior at various strain, temperature and strain rate. The model presented in this study can be used to predict the flow stress of AA2024 aluminum alloys during hot deformation and can be applied to the numerical simulation of the forging, extrusion and stemping processes for AA2024 aluminum alloy.

\section{Acknowledgments}

This work is supported by SUES Innovation Project under grant 14KY0505 and supported by Science Foundation for the Youth Scholars of Shanghai Municipal Education Commission under grant ZZGJD12081.

\section{References}

Atkinson, H. V. (1988). Theories of normal grain growth in pure single phase systems. Acta Metall., 36(3), 469-491. http://dx.doi.org/10.1016/0001-6160(88)90079-X

Chen, F., Cui, Z., Liu, J., Zhang, X., \& Chen, W. (2009). Modeling and simulation on dynamic recrystallization of 30Cr2Ni4MoV rotor steel using the cellular automaton method. Modelling Simul. Mater. Sci. Eng., 17, 1-19. http://dx.doi.org/10.1088/0965-0393/17/7/075015

DeGarmo, P., Black J. T., \& Kohser, R. A. (2003). Materials and Processes in Manufacturing. John Wiley, New York.

Furu, T., Marthinsen, K., \& Nes, E. (1990). Modelling recrystallization. Mater. Sci. Techn., 6(11), 1093-1102.

Humphreys, F. J. (1990). In Proc. Int. Conf. on Recrystallization (pp. 113-122), In T. Chandra (Eds.), Warrendale, PA, TMS.

Liu, J., Cui, Z. S., \& Li, C. X. (2008). Modeling of flow stress characterizing dynamic recrystallization for magnesium alloy AZ31B. Computational Materials Science, 41(3), 375-382. http://dx.doi.org/10.1016/j. commatsci.2007.04.024

McQueen, H. J., \& Ryan, N. D. (2002). Constitutive analysis in hot working. Mater. Sci. Eng., A 322(1-2), 43-63. http://dx.doi.org/10.1016/S0921-5093(01)01117-0

Nes, E., \& Hutchinson, W. B. (1989). In Proc. 10th Riso Int. Symp. on Materials Architechure: the Scientific Basis for Engineering Materials (pp. 233-245). In Bilde-Sorensen J. (Eds.), Roskilde, Denmark, Riso National Labotatory.

Rollett, A. D. (1997). Overview of modeling and simulation of recrystallization. Prog. Mat. Sci., 42, 79-99.

Sellars C. M. (1996). In Thermomechanical Processing in Theory, Modeling \& Practice (pp. 35-51). In Hutchinson B. et al. (Eds.), Swedish Society for Metals Technology.

Sheng, Z. Q., \& Shivpuri, R. (2006). Modeling flow stress of magnesium alloys at elevated temperature. Materials Science and Engineering, 419(1-2), 202-208. http://dx.doi.org/10.1016/j.msea.2005.12.020

Tajally, M., \& Huda, Z. (2011). Recrystallization kinetics for aluminum alloy 7075. Metal science and heat treatment, 53(5-6), 213-217. http://dx.doi.org/10.1007/s11041-011-9371-5

Vatne, H. E., Furu, T., Orsund, R., \& Nes, E. (1996). Modelling recrystallization after hot deformation of aluminium. Acta Mater., 44(11), 4463-4473. http://dx.doi.org/10.1016/1359-6454(96)00078-X

\section{Copyrights}

Copyright for this article is retained by the author(s), with first publication rights granted to the journal.

This is an open-access article distributed under the terms and conditions of the Creative Commons Attribution license (http://creativecommons.org/licenses/by/3.0/). 